\title{
Determination of active compounds in raspberry leaf extracts and the effects of extract intake on mice
}

\author{
Jing YANG ${ }^{1,2 *}(\mathbb{D})$, Jingyan CUI ${ }^{1}$, Hongjuan $\mathrm{HAN}^{1}$, Jinxiang $\mathrm{CHEN}^{1}$, Jingyang $\mathrm{YAO}^{1}$, Yongping $\mathrm{LIU}^{1}$
}

\begin{abstract}
Twelve typical polyphenols in raspberry leaf powder (RLP), raspberry leaf extract 1 (RLE) and raspberry leaf extract 2 (RLE-H) were analyzed by HPLC-MS. The sum of their contents in three samples were in the following order: RLP $\left(8.6 \mathrm{mg} \mathrm{g}^{-1}\right)<$ RLE $\left(35.0 \mathrm{mg} \mathrm{g}^{-1}\right)<\mathrm{RLE}-\mathrm{H}\left(44.1 \mathrm{mg} \mathrm{g}^{-1}\right)$. Ellagic acid and quercetin-3-O-glucuronide were the principal compounds in the samples and accounted for more than $75 \%$ of the sum content. A gelled mixture of RLE, pectin, and sodium alginate administrated to mice via gavage resulted in reduced weight gain and adiposity percentage, increased teste percentage, prolonged exhaustion time, furthermore alleviated intestinal flatulence possibly induced by RLE or RLE-H alone. These results could help in making rational use of this high polyphenol extract from raspberry leaves.
\end{abstract}

Keywords: Rubus idaeus var. reveille; raspberry leaf extract; polyphenols; exhaustive time.

Practical Application: Raspberry leaf extracts, a natural polyphenol material, could be used in the design of nutraceutical supplements.

\section{Introduction}

Raspberry is a multi-functional fruit, which is consumed worldwide for the health benefits of its bioactive natural products, such as anthocyanins and ellagitannins (Aprea et al., 2010). Notably, in Asia and Europe, raspberry leaves are a popular anti-inflammatory and antimicrobial remedy used in traditional medicine (Chinese Pharmacopoeia Commission, 2010; Patel et al., 2004). The total polyphenolic content (TPC) of Rubus fruticosus leaves and Rubus idaeus leaves, determined by the ferric reducing antioxidant power (FRAP) method, were ranked fourth and ninth, respectively, from 70 medicinal plant infusions, which corresponds to a high total antioxidant capacity (Katalinic et al., 2006). Rubus spp. leaves (15 raspberries and 6 blackberries) analyzed by high-performance liquid chromatography (HPLC) indicated that the species were a rich source of flavonoids, ellagic acid (EA), and tannins. Moreover, the content of EA in acid hydrolysis of the samples ranges from $2.06 \%$ to $6.89 \%$ (Gudej \& Tomczyk, 2004). EA derivatives were the predominant compounds in the 26 blackberry leaves analyzed (Oszmianski et al., 2015). Quercetin, widely found in fruits and vegetables, is presently one of the most extensively studied dietary flavonols (an important polyphenol). The quercetin in raspberry leaves is mainly conjugated with glycosides to form quercetin-3-O-glucuronide (Q3G), and quercetin 3-O-rutinoside (rutin). The Q3G content is higher in raspberry leaf extract than in black currant, honeysuckle, bilberry, and strawberry leaf extracts and constitutes $7.5 \%$ by weight of powder (Oszmiański et al., 2011). Further comparative studies of quercetin and Q3G showed that they are equally effective in ameliorating endothelial insulin resistance through inhibition of reactive oxygen species-associated inflammation in vitro (Guo et al., 2013). Although the maximum plasma concentration of quercetin and Q3G for oral administration in rats were $0.75 \mathrm{~h}$ and $5 \mathrm{~h}$, respectively, and the content of the latter in plasma was 18 -fold that of the former, Q3G is a major active component in plasma and tissue (Yang et al., 2016). Therefore, raspberry leaves are also recommended as an alternative source of plant polyphenols.

Although raspberry leaves, have been used in folk medicine for a very long time, the evidence regarding efficacy and active components of the raspberry leaves, as well as the raspberry leaf extracts by organic solvent extraction, macroporous resin purification, and depolymerization by high temperature and high pressure (HTHP), were weak. In addition, it is not clear whether these extracts containing high purity polyphenols are a risk in administration. Therefore, the aim of the present study was to investigate and quantify the 12 polyphenols in leaves and extracts by high-performance liquid chromatography-mass spectrum (HPLC-MS) and determine body indexes, such as body weight, relative organ weight, and exhaustion time, of mice administrated raspberry leaf and extract infusions separately via gavage. These results will be useful for precisely assessing the main active components and the safety of raspberry leaves and extracts.

\section{Materials and methods}

\subsection{Reagents}

Standard sample: brevifolin carboxylic acid (BCA), $(+)$-catechin (C), chlorogenic acid (CA), (-)-epicatechin (EC), ellagic acid (EA), gallic acid, kaempferol-3-O-rutinoside 
(K3R), kaempferol-3-O-glucoside (K3G), proanthocyanidin B1 (B1), kaempferol, quercetin-3-O-rutinoside (rutin), and quercetin-3-O-glucuronide (Q3G) and quercetin were purchased from Shanghai Yuanye Bio-Technology Co. Ltd (Shanghai, China). 1,1-Diphenyl-2-picryl-hydrazyl (DPPH) (Sigma-Aldrich, USA), and Folin-Ciocalteu's phenol (Solarbio, China). AB-8 macroporous resins (Lanxiao Technology New Material Co., Ltd. China) were used in this study. LC/MS-grade methanol, hydrochloric acid, acetic acid, filter membrane and other reagents were purchased from Thermo Fisher Scientific (USA). Pectin with esterification degree less than $60 \%$ was purchased from Silvateam Co. Ltd (Italy) and sodium alginate was purchased Gather Great Ocean Algae Industry group co. Ltd, (Qindao, China).

\subsection{Biological material and experimental design}

1) Raspberry leave powder (RLP) was from Raspberry (Rubus idaeus var. reveille) leaves harvested at plantation of North University of China (E $111^{\circ}, \mathrm{N} 37^{\circ}$ ) in July; 2) Raspberry leaf extract 1 (RLE): raspberry leave powder was extracted using the ultrasonic-assisted ethanol method, in which $25 \mathrm{mg} / \mathrm{mL}$ of powder was extracted in $60 \%$ ethanol at $360 \mathrm{~W}$ for $30 \mathrm{~min}$, using a JOYN-15AL Ultrasonic apparatus (Shanghaiqiaoyue Co., China). The extraction solution was purified by AB-8 macroporous resin and then freeze-dried into a brown powder; 3 ) Raspberry leaf extract 2 (RLE-H): the concentrated RLE solutions were subjected to HTHP treatments $\left(121^{\circ} \mathrm{C}\right.$ and $0.2 \mathrm{MPa}$ for $\left.30 \mathrm{~min}\right)$ using an autoclave (YX-280, Shanghaiqiaoyue Co., China), freeze-dried into powder. Three samples was prepared $10 \mathrm{mg} / \mathrm{mL}$ solution using deionized water at boiling point for $30 \mathrm{~min}$.

\subsection{Total Polyphenolic Content (TPC) and Total Flavonoids Content (TFC)}

TPC of sample solution was determined using Folin-Ciocalteu assay (Meda et al., 2005), and calculated by the following equation based on the gallic acid standard curve: $Y=1.808 X+0.005\left(r^{2}=0.993\right)$; where $\mathrm{Y}$ was the absorbance, and $\mathrm{X}$ was the concentration of gallic acid $\left(\mathrm{mg} \mathrm{mL}^{-1}\right) . T P C /\left(m g g^{-1}\right)=X V / m ; \mathrm{X}$ was solution concentration $\left(\mathrm{mg} \mathrm{mL}^{-1}\right)$; $\mathrm{V}$ was solution volume $(\mathrm{mL})$; $\mathrm{m}$ was the sample weight $(\mathrm{g})$. TFC was determined by the aluminum chloride calorimetric method (Meda et al., 2005). TFC was calculated by the following equation based on the rutin standard curve: $Y=10.696 X+0.0109\left(r^{2}=0.999\right)$; where $\mathrm{Y}$ was the absorbance, and $X$ was the concentration of rutin $(\mathrm{mg} / \mathrm{mL})$. $\mathrm{TFC} /(\mathrm{mg} / \mathrm{g})=\mathrm{nXV} / \mathrm{m}$, where $\mathrm{n}$ was diluted multiples; $\mathrm{X}$ was solution concentration $(\mathrm{mg} / \mathrm{mL})$; $\mathrm{V}$ was solution volume $(\mathrm{mL})$; and $\mathrm{m}$ was the sample weight $(\mathrm{g})$.

\subsection{HPLC-MS analysis}

HPLC-MS analyses were performed on a Thermo Scientific ${ }^{\mathrm{TM}}$ Exactive plus and Q-Exactive HPLC-MS system (Thermo Fisher Scientific Inc, USA). Samples were performed with a Thermo Hypersil GOLD C ${ }_{18}$ column $(100 \mathrm{~mm} \times 2.1 \mathrm{~mm}, 3-\mu \mathrm{m}$ particle size, Thermo Fisher Scientific Inc). A gradient program was divided (phase A water $+0.1 \%$ formic acid) and phase B (acetonitrile). The flow rate was $0.3 \mathrm{~mL} / \mathrm{min}$, and the phase gradient was as follows: $10 \% \mathrm{~B}$ at $0-1.5 \mathrm{~min} ; 10-15 \% \mathrm{~B}$ at $1.5-2.5 \mathrm{~min} ; 15 \%$ at
2.5-4 $\min ; 15-25 \% \mathrm{~B}$ at $4-6 \mathrm{~min} ; 25 \% \mathrm{~B}$ at $6-8 \mathrm{~min} ; 25-70 \%$ at $8-9 \mathrm{~min} ; 70-10 \%$ at $9-10.5 \mathrm{~min}$; and $10 \% \mathrm{~B}$ at $10.5-12 \mathrm{~min}$. The effluents were directed into the MS via the electrospray interface. Nitrogen was used as the nebulizing and drying gas. The detector (MS) operated under the following conditions: electrospray ionization (ESI) interface operating in negative mode; source: $3.5 \mathrm{kV}$; sheath gas flow rate: 40 , auxiliary gas flow: 15 ; capillary temperature: $320^{\circ} \mathrm{C}$ and heater temperature: $300{ }^{\circ} \mathrm{C}$. HPLC-MS was recorded over a mass-to-charge $(\mathrm{m} / \mathrm{z})$ range of 100 to 1,000 . The stock solutions $\left(1 \mathrm{mg} \mathrm{mL}^{-1}\right)$ were filtered through $0.22 \mu \mathrm{m}$ membranes and stored at $-20^{\circ} \mathrm{C}$ before HPLC-MS analysis.

\subsection{Animals}

Eight-week-old specific pathogen-free ICR male mice, each weighing $20.0 \pm 1.0 \mathrm{~g}$, and chow feeds (China National Standard: GB14924.3-2010) were purchased from Shanxi Sheng Experimental Animal Center, China. All mice were housed in a room with a $12: 12 \mathrm{~h}$ light-dark cycle at $22 \pm 1^{\circ} \mathrm{C}$ and received chow feeds with water ad libitum. Phase I: After three days adaptation, 40 mice were randomly divided into four groups ( $\mathrm{n}=10$ per group): a control (CON group, only physiological saline); an RLP group, an RLE group and an RLE-H group. Phase II: after three days adaptation, 40 mice were randomly divided into four groups ( $\mathrm{n}=10$ per group): a CON group, $0.5 \%$ pectin $+0.5 \%$ sodium alginate (PA group); an RLE group; and a $10 \mathrm{mg} / \mathrm{mL} \mathrm{RLE}+0.5 \%$ pectin $+0.5 \%$ sodium alginate (RLEPA group). All samples were prepared in physiological saline ( $0.9 \%$ saline) and dissolved in boiling water at $10 \mathrm{mg} / \mathrm{mL}$ concentration. RLP, RLE, and RLE-H contained $~ 15 \%, \sim 50 \%$, and $\sim 55 \%$ gallic acid equivalent polyphenols. Briefly, $200 \mu \mathrm{L}$ solution/day (i.e. $2.0 \mathrm{mg}$ ) per $20 \mathrm{~g}$ of mouse was administered (i.e., $100 \mathrm{mg}$ powder/day/kg body mass) to the mice via gavage. The solutions contained $300 \mu \mathrm{g}$ of RLP, $1.0 \mathrm{mg}$ of RLE, and $1.1 \mathrm{mg}$ of RLE-H gallic acid equivalent polyphenols, respectively. The hearts, livers, spleens, lung, kidneys, testes, and fat pads were collected and weighed. All animal experiments were carried out following procedures approved by the China National Standard for Laboratory Animals.

\subsection{Animal model of swimming training}

Mice were forced to swimming in groups of three in a plastic bucket $(40 \mathrm{~cm} \times 30 \mathrm{~cm})$ filled with water to a height of $35 \mathrm{~cm}$ and at $30 \pm 1{ }^{\circ} \mathrm{C}$. Endurance capacity of mice was assessed by allowing them to swim with a load of $5.0 \pm 0.13 \%$ of the body weight to exhaustion. The exhaustion was defined as the point when the mice remained below the water surface for $8 \mathrm{~s}$ and the time to exhaustion was recorded in minutes or seconds. Then the mice were killed by cervical dislocations.

\subsection{Body mass index and adiposity calculation}

Body mass index (BMI, $\mathrm{kg} \mathrm{m}^{-2}$ ) was calculated as body weight (kg) divided by body length squared (without tail, $\left.\mathrm{m}^{2}\right)$. Adiposity percentage (\%, API) was determined by the sum of fat tissues (subcutaneous, epididymal, and abdominal) divided by body weight times 100 . Relative organ percentage 
(\%, organ) was determined by organ weight divided by body weight times 100 . For example, testes $(\%)=$ testes $(\mathrm{g}) /$ body weight $(\mathrm{g}) \times 100$.

\subsection{Statistical analysis and flowchart}

All experiments were at least tested with three replicates. The data were statistically treated with ANOVA by SPSS software 19.0 and presented as mean \pm standard deviation (SD). A $p$ value $<0.05$ was considered statistically significant. The flowchart of the experiment was showed Figure 1.

\section{Results and discussion}

\subsection{Changes of major compounds in the raspberry leaves and extracts}

The main active compounds of raspberry leaf infusions and extract infusions were not clear, which limits their application. Therefore, we identified and compared the changes of 12 typical polyphenols in RLP, RLE, and RLE-H by HPLC-MS analysis based on the calibration curves of 12 standard samples (Supplementary Material Table S1) and peak time (Supplementary Material Figure S1). The sum of 12 polyphenolic content ( $\mathrm{TPC}$ ) of the three samples showed increases as follows (Table 1): RLP ( $\left.8.6 \mathrm{mg} \mathrm{g}^{-1}\right)$ $<\operatorname{RLE}\left(35.0 \mathrm{mg} \mathrm{g}^{-1}\right)<\mathrm{RLE}-\mathrm{H}\left(44.1 \mathrm{mg} \mathrm{g}^{-1}\right)$, which corresponded to the TPCs by colorimetry: $144.17 \pm 6.29,503.74 \pm 44.10,540.32$ $\pm 8.96 \mathrm{mg} \mathrm{g}^{-1}$, respectively. The two main compounds in the three samples were Q3G and EA, accounting for 80.39\% in RLP, $76.70 \%$ in RLE, and $82.19 \%$ in RLE-H. Nine compounds in RLE increased at least by $184 \%$, except B1, C, and EC, compared with those in RLP, which indicated the extraction and purification treatment efficiently enriched the active components. Although, $\Sigma$ TPC in RLE-H only increased by $25.94 \%$ compared with the $\Sigma$ TPC in RLE, RLE-H released more EA, from $32.84 \%$ (about 12.7 $\mathrm{mg} \mathrm{g}^{-1}=1.27 \%$ ) in RLE to $55.76 \%$ (about $24.6 \mathrm{mg} \mathrm{g}-1=2.46 \%$ ) in RLE-H. In contrast, there was only $26.45 \%$ Q3G (about 11.7 $\left.\mathrm{mg} \mathrm{g}^{-1}=1.17 \%\right)$ in RLE-H compared with $40.50 \%$ (14.2 $\mathrm{mg} \mathrm{g}^{-1}$ $=1.42 \%$ ) in RLE, and the flavonol glycosides (rutin, K3R, and $\mathrm{K} 3 \mathrm{G}$ ) in RLE-H also reduced by $6.32 \%-32.43 \%$ compared with those in RLE. Moreover, the highest

¿TFC (the sum of 9 flavonoids content) of the three samples was RLE (19.4 $\left.\mathrm{mg} \mathrm{g}^{-1}\right)$, followed by RLE-H $\left(16.9 \mathrm{mg} \mathrm{g}^{-1}\right)$ and RLP (6.4 $\mathrm{mg} \mathrm{g}^{-1}$ ) (Table 1), which corresponded to the TFCs by colorimetry: $264.64 \pm 3.36,252.14 \pm 9.325,63.31 \pm 1.85 \mathrm{mg} \mathrm{g}^{-1}$, respectively. We speculated that a percentage of compounds were partially degraded or depolymerized into smaller molecules after HTHP. For example, the increases of EA may be from the hydrolyzed tannin and EA derivatives, the increases of $\mathrm{C}$ and $\mathrm{EC}$ may be from the depolymerization of $\mathrm{B} 1, \mathrm{~B} 1$ from non-hydrolyzed tannin, and quercetin and kaempferol from all kinds of flavonol glycosides. In our system, simple HTHP conditions without acid were milder than those of HTHP with acid, which would keep a certain balance of EA and Q3G, otherwise only water-insoluble precipitation containing $82 \%$ EA and $16 \%$ quercetin were left in the system (Supplementary Material Table S2), instead of watersoluble EA, Q3G and other polyphenols (Table 1).

\subsection{Mice endurance capacity and weight changes in mice fed extracts}

In order to further identify the edible safety of raspberry leaves as well as raspberry leaf extracts, RLP, RLE, and RLE-H with $15 \mathrm{mg}, 50 \mathrm{mg}$, and $55 \mathrm{mg}$ gallic acid equivalent polyphenols were administrated via gavage of $100 \mathrm{mg} / \mathrm{kg} /$ day for two weeks, respectively. No mice died or had visible diseases during the experimental stage. The body indexes of mice before and after gavage are shown in Table 2. There were significant differences in exhaustion time, final body weight, testes, obesity markers

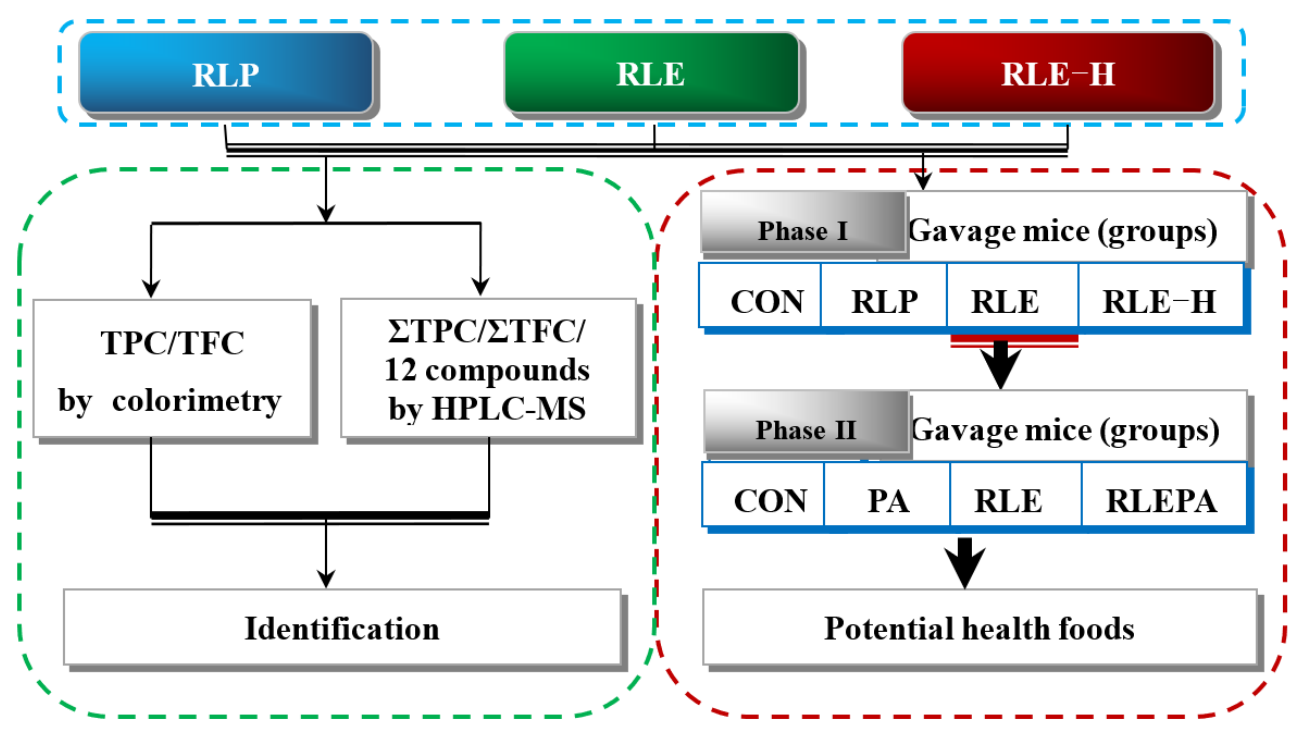

Figure 1. Flowchart of the experiment. RLP = raspberry leaf powder; RLE = raspberry leaf extract 1; RLE-H = raspberry leaf extract 2 from RLE using high temperature and high pressure treatment. The mice via gavage $\mathrm{CON}=$ only physiological saline; $\mathrm{PA}=$ pectin and sodium alginate; RLE = raspberry leaf extract $1 ;$ RLEPA $=$ RLE + pectin + sodium alginate; $\Sigma T P C=$ the sum of 12 polyphenols by HPLC-MS; $\Sigma T F C=$ the sum of 9 flavonoids by HPLC-MS; TPC = total polyphenolic content by colorimetry method; TFC = total flavonoids content by colorimetry method. 


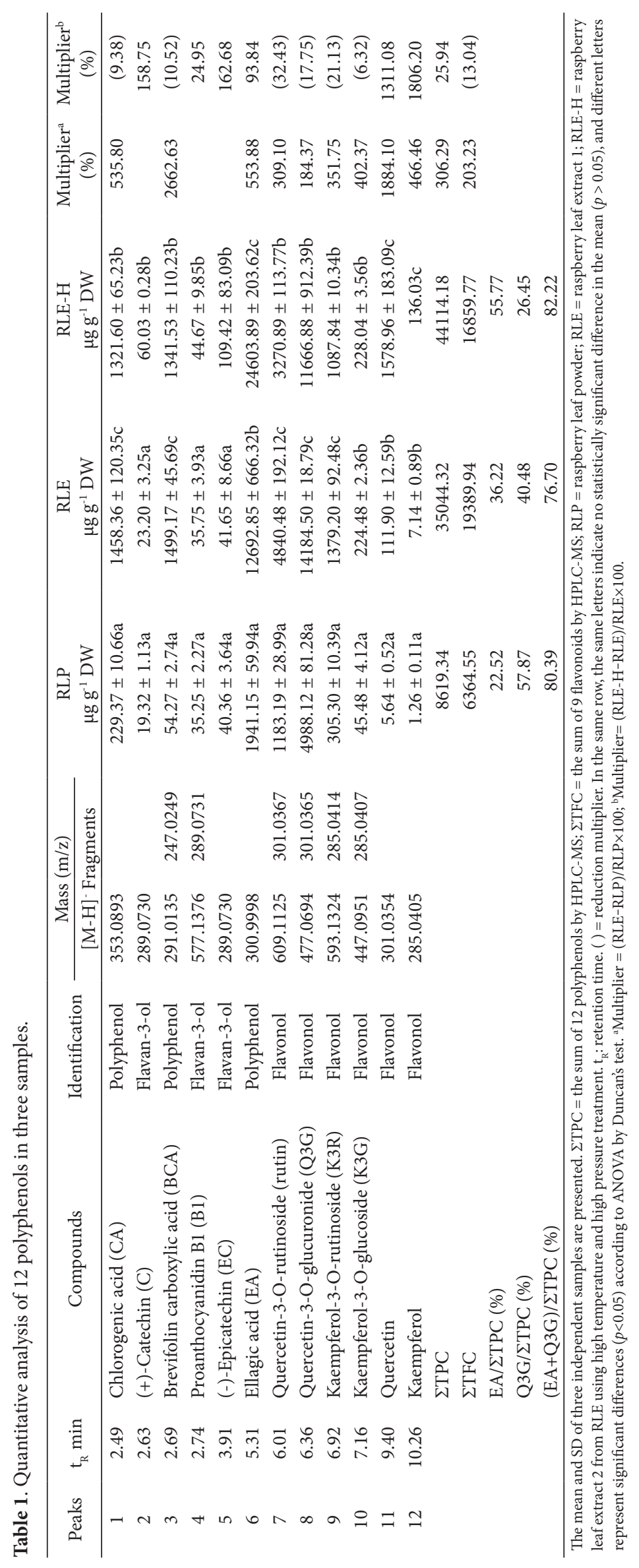


Table 2. Effects of three samples on body weight and exercise capacity in mice.

\begin{tabular}{lcccc}
\hline \multicolumn{1}{c}{ Indexes } & CON group & RLP group & RLE group & RLE-H group \\
\hline Exhaustion time (min) & $50.68 \pm 4.61 \mathrm{a}$ & $58.56 \pm 1.30 \mathrm{a}$ & $102.27 \pm 4.71 \mathrm{~b}$ & $100.27 \pm 6.05 \mathrm{~b}$ \\
Initial body weight (g) & $20.42 \pm 1.73$ & $20.77 \pm 1.48$ & $20.02 \pm 1.80$ & $20.09 \pm 1.79$ \\
Final body weight (g) & $29.87 \pm 3.38 \mathrm{~b}$ & $30.48 \pm 2.81 \mathrm{~b}$ & $26.31 \pm 3.35 \mathrm{a}$ & $23.93 \pm 4.05 \mathrm{a}$ \\
BMI & $3.087 \pm 0.470$ & $3.222 \pm 0.302$ & $2.945 \pm 0.327$ & $2.811 \pm 0.482$ \\
API & $1.84 \pm 0.79 \mathrm{~b}$ & $2.02 \pm 0.44 \mathrm{~b}$ & $1.12 \pm 0.61 \mathrm{a}$ & $0.80 \pm 0.48 \mathrm{a}$ \\
Testes (\%) & $0.65 \pm 0.14 \mathrm{a}$ & $0.76 \pm 0.17 \mathrm{ab}$ & $0.85 \pm 0.13 \mathrm{~b}$ & $0.81 \pm 0.19 \mathrm{ab}$ \\
Heart (\%) & $0.63 \pm 0.09$ & $0.66 \pm 0.05$ & $0.63 \pm 0.10$ & $0.70 \pm 0.35$ \\
Liver (\%) & $6.08 \pm 0.80$ & $6.28 \pm 0.60$ & $6.10 \pm 0.80$ & $6.07 \pm 0.80$ \\
Spleen (\%) & $0.33 \pm 0.11$ & $0.37 \pm 0.10$ & $0.38 \pm 0.23$ & $0.40 \pm 0.13$ \\
Lung (\%) & $1.01 \pm 0.25$ & $1.01 \pm 0.17$ & $1.16 \pm 0.14$ & $1.26 \pm 0.56$ \\
Kidney (\%) & $1.68 \pm 0.30$ & $1.79 \pm 0.30$ & $1.50 \pm 0.22$ & 1 \\
Intestinal flatulence & 0 & 0 & $1.59 \pm 0.39$
\end{tabular}

The mice via gavage $\mathrm{CON}$ = only physiological saline; $\mathrm{RLP}=$ raspberry leaf powder; RLE = raspberry leaf extract 1; RLE-H = raspberry leaf extract 2 from RLE using high temperature and high pressure treatment. Italics indicate: relative organ percentage $(\%$, organ), e.g. Testes $=($ Testes $(\mathrm{g}) /$ Final body weight $(\mathrm{g})) \times 100$. In the same row, the same letters indicate no statistically significant difference in the mean $(p>0.05)$, and different letters represent significant differences $(p<0.05)$ according to ANOVA by Duncan's test.

(BMI, body fat mass, and API) in the four groups $(p<0.05)$, but other indexes were not significantly different $(p>0.05)$.

Firstly, after two weeks the final body weight, API and BMI of the RLE and RLE-H groups were significantly decreased $(p<0.05)$ compared with the CON and RLP groups, and the testes of RLP, RLE, and the RLE-H groups were significantly larger than those of the CON group $(p<0.05)$, which implied that the effects of raspberry leaves or extracts on mouse bodies were dose-effective. The effect of raspberry leaves and extracts on the testes may well confirm the efficacy of raspberry in reducing urine, repairing sperm, and improving renal functions, which were recorded in the Chinese Pharmacopoeia Commission (2010). It was reported that isocaloric diets containing freeze-dried raspberries, improved antioxidant status by $5.3 \%$ and lessened plasma interleukin (IL)- 6 content ( 0.3 -fold of control isocaloric diets, $p<0.1)$. Raspberry intake at this dose led to no difference in BMI, API, and weights of heart, liver, or kidney between the raspberry and control group, which were similar to the results of the RLP group, but there were no testes data (Noratto et al., 2017). Raspberry juice and puree concentrates and the combination of EA+raspberry ketone (RK) decreased weight gain and obesity in high-fat-fed mice (Luo et al., 2016).

Secondly, the exhaustion swimming time of RLE and RLE-H groups were significantly prolonged compared with the CON and RLP groups. It is not clear whether the extracts improved the exercise ability of mice by reducing the body weight gain or not. However, grape seed extract containing proanthocyanidin 95\% (Xianchu et al., 2018) and (-)-epigallocatechin-3-gallate, green tea polyphenols (Teng \& Wu, 2017) and polysaccharides extracted from Hericium erinaceus (Liu et al., 2015) prolonged dose-dependently the exhaustive swimming time of mice and delayed fatigue.

Thirdly, EA from raspberry seed flour (equivalent to $0.03 \%$ of EA), considered the most important component, significantly improved high-sucrose diet-mediated dyslipidemia and restored glucose homeostasis levels similar to the high-fat-diet-fed mice (Kang et al., 2016). EA and RK were each added at $0.2 \%(\mathrm{w} / \mathrm{w})$ to provide a total supplement of $0.4 \%(\mathrm{w} / \mathrm{w})$ high-fat diet, which reduced the development of obesity (Luo et al., 2016). The dietary concentration of EA+RK is consistent with the human intake of phytochemical based dietary supplements. In our study, RLP, RLE, and RLE-H contained about $0.2 \%, 1.3 \%$, and $2.5 \%$ EA, respectively. The latter two doses may be too high for healthy mice via gavage, which may have caused the adverse intestinal flatulence in the RLE and RLE-H groups found in the anatomical results (Table 2 and Supplementary Material Figure S2). Altogether, these results suggest that low doses of active phenols may modulate various physiological indexes, while high doses such as RLE and RLE-H may decrease body weight gain and improve exercise ability, but may bring about intestinal risk.

\subsection{Mice endurance capacity and weight changes in mice fed extracts with pectin and sodium alginate}

Sodium alginate from brown seaweed and pectin from plants are soluble dietary fiber and have been used as a hemostatic agent to treat gastrointestinal bleeding due to gastric ulcers (Horibe et al., 2016; Satoh et al., 2016). To solve the intestinal flatulence that may be caused by the intake of high-dose extract, RLE with pectin and sodium alginate with boiling water was prepared into a gelled food for the mice. The results indicated that the exhaustion times of the PA, RLE, RLEPA groups were significantly prolonged, and the final body weight, API, and BMI of the three groups were significantly decreased compared with the CON group (Table 3). It is worth noting that the gelled mixture of RLE, pectin and sodium alginate not only maintained the beneficial effect of RLE in testes growth, but also solved the problem of intestinal flatulence possibly caused by high intake of RLE, and the weight of RLEPA groups remained unchanged before and after administration, compared with a reduction in weight gain in the PA and RLE groups. We speculated that the viscosities of pectin and sodium alginate may be beneficial to the formation of a protective film on the surface of the gastrointestinal tract and to the reduction of direct mucosal damage caused by high doses of drugs. Nonsteroidal anti-inflammatory drugs (indomethacin, diclofenac, and loxoprofen) often have a limited 
Yang et al.

Table 3. Effects of RLE and mixtures on body weight and exercise capacity in mice.

\begin{tabular}{lcccc}
\hline \multicolumn{1}{c}{ Indexes } & CON group & PA group & RLE group & RLEPA group \\
\hline Exhaustion time (min) & $49.13 \pm 1.16 \mathrm{a}$ & $105.48 \pm 9.11 \mathrm{~b}$ & $117.39 \pm 10.951 \mathrm{~b}$ & $110.74 \pm 7.34 \mathrm{~b}$ \\
Initial body weight $(\mathrm{g})$ & $20.95 \pm 2.18$ & $19.95 \pm 1.65$ & $20.66 \pm 1.84$ & $20.79 \pm 2.65$ \\
Final body weight $(\mathrm{g})$ & $31.81 \pm 3.96 \mathrm{c}$ & $25.18 \pm 2.50 \mathrm{~b}$ & $24.40 \pm 1.26 \mathrm{~b}$ & $20.85 \pm 3.05 \mathrm{a}$ \\
BMI & $3.17 \pm 0.70 \mathrm{c}$ & $2.816 \pm 5.67 \mathrm{~b}$ & $2.745 \pm 0.327 \mathrm{~b}$ & $2.652 \pm 0.61 \mathrm{a}$ \\
API & $1.78 \pm 0.79 \mathrm{~b}$ & $1.57 \pm 0.44 \mathrm{ab}$ & $1.34 \pm 0.61 \mathrm{a}$ & $1.25 \pm 0.48 \mathrm{a}$ \\
Testes (\%) & $0.70 \pm 0.14 \mathrm{a}$ & $0.77 \pm 0.17 \mathrm{a}$ & $0.88 \pm 0.13 \mathrm{~b}$ & $0.95 \pm 0.19 \mathrm{~b}$ \\
Intestinal flatulence & 0 & 0 & 1 & 0 \\
\hline
\end{tabular}

The mice via gavage $\mathrm{CON}=$ only physiological saline; $\mathrm{PA}=$ pectin and sodium alginate; RLE $=$ raspberry leaf extract $1 ; \mathrm{RLEPA}=\mathrm{RLE}+$ pectin + sodium alginate. Italics indicate: relative organ percentage $(\%$, organ $)$, e.g. Testes $=($ Testes $(\mathrm{g}) /$ Final body weight $(\mathrm{g})) \times 100$. In the same row, the same letters indicate no statistically significant difference in the mean $(p>0.05)$, and different letters represent significant differences $(p<0.05)$ according to ANOVA by Duncan's test.

use due to serious adverse effects on the gastrointestinal tract and kidneys. However, small-intestinal injury induced by these drugs was restored and inhibited by feeding powdered CE- 2 containing $5 \%(w / v)$ sodium alginate (Horibe et al., 2016) and a regular diet containing 1-10\% $(w / v)$ pectin (Satoh \& Urushidani, 2016). This protection mechanism is also involved in decreasing the mRNA expression of the mucin gene family (Muc1, Muc2, Muc3, and Muc4) in the small intestine (Horibe et al., 2016). Moreover, calcium-gelled, alginate-pectin beverage may provide satiety to reduce energy intake in nondieting over weight and obese women (Pelkman et al., 2007). In an assessment of 30 healthy volunteers, after ingestion of gelled pectin, the appetite was reduced and gastric emptying rate was extended compared to then one pectin groups, but there was no difference in the subsequent energy intake of all groups (Wanders et al., 2014). Therefore, the gelled mixture of raspberry leaf extract, pectin, and sodium alginate could be further developed into health foods, such as diet jelly or diet granules.

\section{Conclusion}

The present study did not specifically address the mechanism(s) of raspberry leaf powder or extracts on food intake, body weight, BMI, API, and the testes of mice. Nevertheless, some conclusions may be put forward on account of the findings available to date: 1) Raspberry leaves and extracts contain high levels of polyphenols, the most important compounds of which are EA+Q3G (>75\%); 2) the intake of raspberry leaf extract is conducive to decreasing weight gain and API, increasing testes weight, and prolonging exhaustion time; 3 ) the gelled mixture of RLE, pectin and sodium alginate not only alleviated intestinal flatulence caused by the direct intake of extracts, but also maintained mouse weight. Therefore, raspberry leaves, especially extracts, could be ideal natural sources of polyphenols and used to design nutraceutical supplements.

\section{Acknowledgements}

This work was supported by Open project of Key Laboratory of Urban Agriculture (North) of Ministry of Agriculture (KFK2015001), "1331 Project” Graduate Education Innovation Project of Shanxi Province (No. 2017SY067) and the National Natural Science Foundation of China for Youth (No. 31200462).

\section{References}

Aprea, E., Carlin, S., Giongo, L., Grisenti, M., \& Gasperi, F. (2010). Characterization of 14 raspberry cultivars by solid-phase microextraction and relationship with gray mold susceptibility. Journal of Agricultural and Food Chemistry, 58(2), 1100-1105. http://dx.doi.org/10.1021/ jf902603f. PMid:20025221.

Chinese Pharmacopoeia Commission. (2010). The Chinese Pharmacopoeia (Vol. 1). Beijing: China Medical Science Press.

Gudej, J., \& Tomczyk, M. (2004). Determination of flavonoids, tannins and ellagic acid in leaves from Rubus L. species. Archives of Pharmacal Research, 27(11), 1114-1119. http://dx.doi.org/10.1007/BF02975114. PMid:15595412.

Guo, X. D., Zhang, D. Y., Gao, X. J., Parry, J., Liu, K., Liu, B. L., \& Wang, M. (2013). Quercetin and quercetin-3-O-glucuronide are equally effective in ameliorating endothelial insulin resistance through inhibition of reactive oxygen species-associated inflammation. Molecular Nutrition \& Food Research, 57(6), 1037-1045. http:// dx.doi.org/10.1002/mnfr.201200569. PMid:23504962.

Horibe, S., Tanahashi, T., Kawauchi, S., Mizuno, S., \& Rikitake, Y. (2016). Preventative effects of sodium alginate on indomethacin-induced small-intestinal Injury in mice. International Journal of Medical Sciences, 13(9), 653-663. http://dx.doi.org/10.7150/ijms.16232. PMid:27647994.

Kang, I., Espin, J. C., Carr, T. P., Tomas-Barberan, F. A., \& Chung, S. (2016). Raspberry seed flour attenuates high-sucrose diet-mediated hepatic stress and adipose tissue inflammation. The Journal of Nutritional Biochemistry, 32, 64-72. http://dx.doi.org/10.1016/j. jnutbio.2016.02.006. PMid:27142738.

Katalinic, V., Milos, M., Kulisic, T., \& Jukic, M. (2006). Screening of 70 medicinal plant extracts for antioxidant capacity and total phenols. Food Chemistry, 94(4), 550-557. http://dx.doi.org/10.1016/j. foodchem.2004.12.004.

Liu, J., Du, C., Wang, Y., \& Yu, Z. (2015). Anti-fatigue activities of polysaccharides extracted from Hericium erinaceus. Experimental and Therapeutic Medicine, 9(2), 483-487. http://dx.doi.org/10.3892/ etm.2014.2139. PMid:25574220.

Luo, T., Miranda-Garcia, O., Adamson, A., Sasaki, G., \& Shay, N. F. (2016). Development of obesity is reduced in high-fat fed mice fed whole raspberries, raspberry juice concentrate, and a combination of the raspberry phytochemicals ellagic acid and raspberry ketone. Journal of Berry Research, 6(2), 213-223. http://dx.doi.org/10.3233/ JBR-160135.

Meda, A., Lamien, C. E., Romito, M., Millogo, J., \& Nacoulma, O. G. (2005). Determination of the total phenolic, flavonoid and proline contents in Burkina Fasan honey, as well as their radical scavenging 
activity. Food Chemistry, 91(3), 571-577. http://dx.doi.org/10.1016/j. foodchem.2004.10.006.

Noratto, G. D., Chew, B. P., \& Atienza, L. M. (2017). Red raspberry (Rubus idaeus L.) intake decreases oxidative stress in obese diabetic $(\mathrm{db} /$ db) mice. Food Chemistry, 227, 305-314. http://dx.doi.org/10.1016/j. foodchem.2017.01.097. PMid:28274436.

Oszmiański, J., Wojdylo, A., Gorzelany, J., \& Kapusta, I. (2011). Identification and characterization of low molecular weight polyphenols in berry leaf extracts by HPLC-DAD and LC-ESI/ MS. Agricultural and Food Chemistry, 59(24), 12830-12835. http:// dx.doi.org/10.1021/jf203052j. PMid:22098480.

Oszmianski, J., Wojdylo, A., Nowicka, P., Teleszko, M., Cebulak, T., \& Wolanin, M. (2015). Determination of phenolic compounds and antioxidant activity in leaves from wild Rubus L. species. Molecules, 20(3), 4951-4966. http://dx.doi.org/10.3390/molecules20034951. PMid:25793543.

Patel, A. V., Rojas-Vera, J., \& Dacke, C. G. (2004). Therapeutic constituents and actions of Rubus species. Current Medicinal Chemistry, 11(11), 1501-1512. http://dx.doi.org/10.2174/0929867043365143. PMid:15180580.

Pelkman, C. L., Navia, J. L., Miller, A. E., \& Pohle, R. J. (2007). Novel calcium-gelled, alginate-pectin beverage reduced energy intake in nondieting overweight and obese women: interactions with dietary restraint status. The American Journal of Clinical Nutrition, 86(6), 1595-1602. http://dx.doi.org/10.1093/ajcn/86.5.1595. PMid:18065575.

Satoh, H., \& Urushidani, T. (2016). Soluble dietary fiber can protect the gastrointestinal mucosa against nonsteroidal anti-Inflammatory drugs in mice. Digestive Diseases and Sciences, 61(7), 1903-1914. http://dx.doi.org/10.1007/s10620-016-4086-5. PMid:26921081.

Satoh, H., Matsumoto, H., Hirakawa, T., \& Wada, N. (2016). Soluble dietary fibers can protect the small intestinal mucosa without affecting the anti-inflammatory effect of indomethacin in adjuvant-induced arthritis rats. Digestive Diseases and Sciences, 61(1), 91-98. http://dx.doi.org/10.1007/s10620-015-3889-0. PMid:26423078.

Teng, Y. S., \& Wu, D. (2017). Anti-fatigue effect of green tea polyphenols (-)-epigallocatechin-3-gallate (EGCG). Pharmacognosy Magazine, 13(50), 326-331. http://dx.doi.org/10.4103/0973-1296.204546. PMid:28539729.

Wanders, A. J., Feskens, E. J., Jonathan, M. C., Schols, H. A., de Graaf, C., \& Mars, M. (2014). Pectin is not pectin: a randomized trial on the effect of different physicochemical properties of dietary fiber on appetite and energy intake. Physiology \& Behavior, 128, 212-219. http://dx.doi.org/10.1016/j.physbeh.2014.02.007. PMid:24534170.

Xianchu, L., Ming, L., Xiangbin, L., \& Lan, Z. (2018). Grape seed proanthocyanidin extract supplementation affects exhaustive exerciseinduced fatigue in mice. Food \& Nutrition Research, 62(1421), 1-7. http://dx.doi.org/10.29219/fnr.v62.1421. PMid:29904333.

Yang, L., Xiao, N., Li, X., Fan, Y., Alolga, R. N., Sun, X., Wang, S. L., Li, P., \& Qi, L. W. (2016). Pharmacokinetic comparison between quercetin and quercetin 3-O- $\beta$-glucuronide in rats by UHPLCMS/MS. Scientific Reports, 6(1), 35460. http://dx.doi.org/10.1038/ srep35460. PMid:27775094. 


\section{Supplementary Material}

Supplementary material accompanies this paper.

Figure S1. HPLC chromatogram of the three extracts.

Figure S2. The anatomical drawing of mice

Table S1. Calibration curves for 12 standard compounds.

Table S2. Quantitative analysis of polyphenols in the RLE with or without acid.

This material is available as part of the online article from http://www.scielo.br/cta. 